\title{
Bacteria could help ectomycorrhizae establishment under climate variations
}

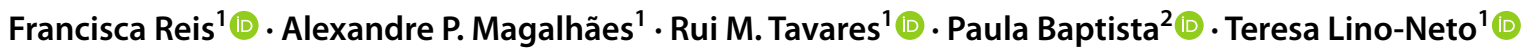

Received: 16 November 2020 / Accepted: 8 March 2021 / Published online: 29 March 2021

(c) The Author(s), under exclusive licence to Springer-Verlag GmbH Germany, part of Springer Nature 2021

\begin{abstract}
Rhizosphere microbiome is one of the main sources of plant protection against drought. Beneficial symbiotic microorganisms, such as ectomycorrhizal fungi (ECMF) and mycorrhiza helper bacteria (MHB), interact with each other for increasing or maintaining host plant fitness. This mutual support benefits all three partners and comprises a natural system for drought acclimation in plants. Cork oak (Quercus suber L.) tolerance to drought scenarios is widely known, but adaptation to climate changes has been a challenge for forest sustainability protection. In this work, ECMF and MHB communities from cork oak forests were cross-linked and correlated with climates. Cenococcum, Russula and Tuber were the most abundant ECMF capable of interacting with MHB (ECMF MHB) genera in cork oak stands, while Bacillus, Burkholderia and Streptomyces were the most conspicuous MHB. Integrating all microbial data, two consortia Lactarius/Bacillaceae and Russula/Burkholderaceae have singled out but revealed a negative interaction with each other. Russula/Burkholderaceae might have an important role for cork oak forest sustainability in arid environments, which will be complemented by the lower drought adaptation of competitive Lactarius/Bacillaceae. These microbial consortia could play an essential role on cork oak forest resilience to upcoming climatic changes.
\end{abstract}

Keywords Mycorrhiza helper bacteria $\cdot$ Ectomycorrhizae $\cdot$ Cork oak $\cdot$ Symbiotic relation

\section{Introduction}

The prediction of a global climate change for the next century is one of the main threats to forest ecosystem sustainability. Mediterranean forest in particular is considered as one of the major global biodiversity hotspots, due to its rich biodiversity, comprising many endemic species that are being threatened by anthropogenic and climate challenges (Pausas and Millán 2019). These forests are mainly composed by broadleaved evergreen tree species (holm-Quercus ilex and cork oak-Quercus suber). More than half of world cork oak forests are located within the Mediterranean basin region, where trees with the highest economic value reside

Teresa Lino-Neto

tlneto@bio.uminho.pt

1 BioSystems \& Integrative Sciences Institute (BioISI), Plant Functional Biology Centre, University of Minho, Campus de Gualtar, 4710-057 Braga, Portugal

2 Centro de Investigação de Montanha (CIMO), Instituto Politécnico de Bragança, Campus de Santa Apolónia, 5300-253 Braganca, Portugal in Portugal, the largest producer of cork (53\% of world production) (APCOR, 2019). Q. suber grows in different forest systems depending on tree density, montados (or dehesas) and sobreirais, comprising low-density stands with 60-100 trees/ha to approximately 400 trees/ha, respectively. This cork oak density and tree distribution are closely related to water availability. Climate changes, such as increased temperatures and reduction of water availability, are currently posing a challenge to cork oak forests (reviewed by Reis et al. 2017; Maghnia et al. 2019). Since a reduction in water availability is expected soon (Malek and Verburg 2018), decrease in $Q$. suber growth and productivity, as well as the long-term sustainability of these ecosystems, may be further threatened (Acácio et al. 2010).

From the huge diversity of microbes, beneficial soil microorganisms are widely known by improving plant health and stimulate plant growth. Ectomycorrhizal fungi (ECMF) play an essential role for plant drought stress resistance, being strongly associated with forest tree sustainability, namely within temperate Fagaceae forests (Reis et al. 2017). Although fungal communities are more related with water transfer and increasing water availability to plants 
(Bonfante and Genre 2010), bacterial communities have been reported to change with precipitation levels (Felsmann et al. 2015), drought (Bastida et al. 2019) and season (López-Mondéjar et al. 2015). In the specific group of symbiotic bacteria, plant growth-promoting rhizobacteria (PGPR) can play an important role on drought tolerance (Reis et al. 2018). PGPR colonises rhizosphere and can be free living or develop close associations to plant roots (Backer et al. 2018). Within PGPR group, mycorrhizae helper bacteria (MHB) specifically interact with mycorrhizal fungi, stimulating mycelium extension, increasing the colonisation and contact of host roots, as well as reducing environmental changes for attaining optimal conditions for mycelium growth (Frey-Klett et al. 2007). One of the most studied ecological advantages of MHB is the improvement of drought tolerance they provide to host plants (Forchetti et al. 2007). Therefore, plants are not only colonised by fungi but also by symbiotic bacteria, such as mycorrhiza helpers that confer beneficial effects to their hosts (Compant et al. 2010). Such interactions are highly specific, and MHB could select the most appropriated ECMF for plant symbiosis (reviewed by Frey-Klett et al. 2007). Distinct ECM fungal isolates respond differentially to the same MHB, even when using different strains of the same ECMF species. The discovery of new specific microbial partners that together enhance the establishment and maintenance of mycorrhizae has been based on functional studies performed with moderately easily cultivable ECMF and a reduced selection of cultivable bacteria (Labbé et al, 2014). The use of data obtained through non-cultivable approaches, such as high throughput sequencing or ECM root tips barcoding, could give new hints about specific interactions. The ectomycorrhizal and bacterial communities from the rhizosphere of cork oaks inhabiting distinct climates was recently evaluated by Reis et al. $(2018,2019)$. Both communities presented differences regarding a water gradient, but their interaction was not addressed. In an attempt to suggest new partners of ECMF and soil bacteria, we have correlated the abundance of both communities in cork oak forests displaying different water availabilities, in order to select those partners that are simultaneously affected by drought. In addition, we investigated the relation between ECMF and MHB communities identified in cork oak stands under a drought gradient.

\section{Material and methods}

\section{Forests and sample collection}

Cork oak forests from seven geographic locations in Portugal were sampled based on water availability and local weather (Portuguese Sea and Atmosphere Institute). Their Mediterranean climate was determined through determination of
Emberger indexes $(Q)$ that considers the annual precipitation (Pannual), as well as the maximal (Tmax) and minimal (Tmin) temperatures of the hottest and coldest months, respectively, during the sampling year $(Q=100$ Pannual/ $\left(\operatorname{Tmax}^{2}-\mathrm{Tmin}^{2}\right)$; Tate and Gustard 2000). Based on annual precipitation means, Peneda-Gerês (PG, $1448.4 \mathrm{~mm}$ ) and Herdade da Contenda (HC, $558 \mathrm{~mm}$ ) comprised the extreme conditions. Two independent forests were sampled in each of these locations (PG-ER and PG-RC; HC-CT and HC-MA). Other three locations displaying intermediate precipitation levels were also sampled [Limãos (LI, $772.8 \mathrm{~mm}$ ), Alcobaça (AL, $735.6 \mathrm{~mm}$ ), and Grândola (GR, $651.6 \mathrm{~mm}$ )]. The sampled forests were separated into four distinct Mediterranean climates: humid (PG, $Q=186.6$ ), sub-humid (LI, $Q=88.9$; $\mathrm{AL}, Q=102.7$ ), semi-arid (GR, $Q=77.5$ ) and arid (HC, $Q=43.5$ ). The same soil samples were used for assessing ectomycorrhizal communities (through root tips barcoding, Reis et al. 2018) and bacterial communities (through metabarcoding, Reis et al. 2019). In each forest, five independent healthy trees (plots) were selected, separated at least $30 \mathrm{~m}$ from each other. From each plot, three soil cores $(8 \mathrm{~cm}$ of diameter and $12 \mathrm{~cm}$ in depth) were collected under the middle of the cork oak canopy, in three tree trunk directions. In total, 105 soil cores ( 7 forests $\times 5$ trees $\times 3$ cores) were collected.

\section{Statistical and ecological data analysis}

Fungal sequences identified through ITS barcoding of ECM tips were analysed (Reis et al. 2018) and those ECMF OTUs able of interacting with MHB (ECMF MHB) were selected, based on their description in the literature (FreyKlett et al. 2007; Kataoka et al. 2009; Rigamonte et al. 2010; Kurth et al. 2013; Egamberdieva et al. 2017). Bacterial OTUs identified by using $16 \mathrm{~S}$ metabarcoding approaches (Reis et al. 2019) were screened for MHB OTUs, based on the information in the literature (Ząbkiewicz et al. 2014). Selected ECMF MHB and MHB OTUs were used for further analyses.

A correlation between community structure and geographic distances was determined using the Mantle test of the Microsoft Excel add-in program XLSTAT version 2017 (Addinsoft, New York, USA). Pearson's correlations between climatic conditions and fungal structure were performed with Excel tools. One-way ANOVA followed by Tukey's multiple comparison test was performed using the analysis tools of GraphPad Prism 7 (La Jolla California, USA). At first, a correlation-based network was generated from all ECMF and soil bacterial communities, using the raw counts for each OTU and the methods described in Ju et al. (2014). Shortly, the raw counts for each sample were filtered to remove any OTUs with less than 12 sample occurrences. The co-occurrence network was calculated by 
applying pairwise Spearman's rank correlations between all filtered OTUs, using a cut-off of 0.6 for Spearman's correlation coefficient and the $p$ value of 0.01 . The above analysis was performed using $R$ (Ihaka and Gentleman 1996) and Cytoscape (Shannon et al. 2003) for network visualisation. A second more focused correlation-based network was generated using ECMF MHB and MHB OTUs.

\section{Results and discussion}

ECM root tips sampled on cork oak forests resulted in 32 ECM fungal genera and 136 species. From these, only 11 genera (52 species) have been described as capable of being influenced by MHB, namely Amanita, Boletus, Cantharellus, Cenococcum, Hebeloma, Laccaria, Lactarius, Piloderma, Pisolithus, Russula and Tuber (Supplementary Table S1; Frey-Klett et al. 2007; Kataoka et al. 2009; Rigamonte et al. 2010; Kurth et al. 2013; Egamberdieva et al. 2017).

Table 1 Relative abundance (RA) and Pearson's correlations between ECMF MHB/MHB relative abundance and climate parameters [average precipitation and temperatures from the past 30 years (19862016; aver), from the wettest/hottest month (max) and from the driest/
Although Frey-Klett et al. (2007) referred to Basidiomycetes as the only ECMF capable of interacting with MHB (ECMF MHB), more recent studies revealed that Ascomycetes, such as Cenococcum geophilum, are also able to cooperate with Bacillus subtilis (Kataoka et al. 2009). The identified ECMF MHB only represents $38.10 \%$ of identified ECMF species, but their abundance in overall cork oak rhizosphere reaches $54.89 \%$ of total ECMF abundance (Table 1). Moreover, the relative abundance of ECMF MHB is significantly affected by geographic location $(p<0.05$, ANOVA). Three out of 11 genera of ECMF MHB exhibit different relative abundances among cork oak forests, namely Cenococcum, Russula and Tuber ( $p<0.05$, ANOVA; Supplementary Table S1).

Cork oak bacterial community survey was performed by metabarcoding approach using an Illumina platform (Reis et al. 2019), being found a large abundance of symbiotic bacteria (2.79\% of all identified reads; Table 1$)$. From the 5329 identified bacterial OTUs with at least 5 reads in all the

coldest month (min) of the sampling year], as well as with indexes of Emberger $(Q)$. TOTAL comprises pooled ECMF MHB or MHB identified reads

\begin{tabular}{|c|c|c|c|c|c|c|c|c|}
\hline \multirow[t]{2}{*}{ Microbial taxa } & \multirow[t]{2}{*}{$\mathrm{RA}(\%)$} & \multicolumn{3}{|l|}{ Precipitation } & \multicolumn{3}{|c|}{ Temperature } & \multirow[t]{2}{*}{$Q$} \\
\hline & & Aver & $\operatorname{Max}$ & Min & Aver & Max & Min & \\
\hline \multicolumn{9}{|l|}{ ECMF MHB } \\
\hline Amanita & 0.65 & 0.57 & 0.67 & 0.08 & -0.20 & -0.58 & 0.38 & 0.50 \\
\hline Boletus & 1.71 & 3.53 & 3.45 & 3.49 & -3.61 & -2.69 & -0.18 & 3.37 \\
\hline Cantharellus & 3.56 & $7.21 *$ & $7.26 *$ & $5.49 *$ & -6.49 & -3.58 & 0.01 & $6.41 *$ \\
\hline Cепососсит & 10.24 & 0.83 & 1.04 & 0.01 & -0.25 & 0.00 & 2.79 & 0.41 \\
\hline Hebeloma & 0.73 & 2.50 & 2.52 & 1.96 & -2.28 & -1.32 & 0.00 & 2.25 \\
\hline Laccaria & 0.67 & -0.16 & -0.14 & -0.23 & 0.13 & 0.80 & 0.18 & -0.38 \\
\hline Lactarius & 6.82 & 0.80 & 0.71 & 0.32 & -0.27 & -0.20 & 1.23 & 2.45 \\
\hline Piloderma & 0.14 & -0.39 & -0.45 & -0.53 & 0.77 & 0.30 & 0.63 & 0.00 \\
\hline Pisolithus & 0.03 & -0.78 & -0.73 & -0.83 & 0.67 & 1.63 & 0.17 & -1.18 \\
\hline Russula & 28.67 & $-8.76 * *$ & $-8.77 * *$ & -3.71 & $4.52 *$ & 4.02 & -2.61 & $-13.93 * * *$ \\
\hline Tuber & 1.68 & -0.51 & -0.36 & -1.70 & 1.17 & 0.15 & 0.96 & -0.74 \\
\hline TOTAL & 54.89 & -0.40 & -0.23 & -1.41 & 0.60 & 1.17 & 0.99 & -1.78 \\
\hline \multicolumn{9}{|l|}{ МHB } \\
\hline Arthrobacter & 0.13 & 2.28 & 2.55 & 1.05 & -1.75 & -1.10 & 0.17 & 1.24 \\
\hline Bacillus & 0.83 & $-17.42 * * *$ & $-9.71 * *$ & $-12.26^{* *}$ & $10.10 * *$ & $12.80 * *$ & 0.78 & $-17.42 * * *$ \\
\hline Bradyrhizobium & 0.04 & -0.02 & -0.03 & 0.00 & 0.00 & 0.24 & 0.00 & -0.06 \\
\hline Burkholderia & 0.93 & 1.21 & 0.87 & 3.81 & -1.93 & $-5.98^{*}$ & $-5.02 *$ & 0.00 \\
\hline Pseudomonas & 0.44 & -0.45 & -0.71 & 0.10 & 0.08 & -0.41 & $-4.55 *$ & 0.00 \\
\hline Rhizobium & 0.15 & $-9.86 * *$ & $-11.47 * *$ & -3.00 & $6.90 *$ & 0.41 & $-4.37 *$ & $-4.18^{*}$ \\
\hline Streptomyces & 0.66 & $-16.03 * * *$ & $-15.68 * * *$ & $-12.88 * *$ & $15.38 * * *$ & $4.24 *$ & -0.05 & $-14.47 * * *$ \\
\hline TOTAL & 2.79 & $-7.41 *$ & $-7.58 * *$ & $-4.25 *$ & $5.71 *$ & 1.76 & -0.87 & $-6.85^{*}$ \\
\hline
\end{tabular}

Statistically significant correlations are highlighted in bold

Statistical significance at

$* p<0.05 ; * * p<0.01 ; * * * p<0.001$ 
analysed soil samples, 19 have been described as acting as MHB. The identified OTUs belong to the genera Arthrobacter, Bacillus, Bradyrhizobium, Burkholderia, Pseudomonas, Rhizobium and Streptomyces (Supplementary Table S1). Only five OTUs were identified up to species level, namely Bacillus cereus, Burkholderia xenovorans, Burkholderia humi, Rhizobium tubonense and Streptomyces neopeptinius. Within MHB, functional groups can be distinguished based on the bacterial ability to interact with ECMF, arbuscular mycorrhizal (AR) fungi, or both (Frey-Klett et al. 2007). Arthrobacter is the only identified genus capable of only interacting with ECMF species, whereas Bradyrhizobium and Rhizobium have been described to be only associated to AR fungi (Glomus sp.; Frey-Klett et al. 2007; Rigamonte et al. 2010; Egamberdieva et al. 2017). Burkholderia exhibits a mixed interaction pattern, being associated with AR but also with ECMF (Poole et al. 2001). Altogether, the bacterial genera that can interact with ECMF is 1.9-fold more abundant than AR-specific genera, agreeing with the fact that they were found in forest ecosystems. Regarding their relative abundance, nine out of 19 bacterial MHB OTUs reveal significant differences among cork oak forests $(p<0.05$, ANOVA; Supplementary Table S1). All these species belong to the three (out of seven) evaluated MHB genera that also present differences among cork oak forests, namely Bacillus, Burkholderia and Streptomyces ( $p<0.05$, ANOVA). Bacillus and Streptomyces genera, but also Pseudomonas, are the most studied MHB and are known to promote plant growth through the production of phytohormones (indole acetic acid-IAA; Egamberdieva et al. 2017) and siderophores (Pii et al. 2015).

Cork oak ectomycorrhizal community has been correlated with several climatic parameters, such as precipitation and temperature, as well as land use practices (Azul et al. 2010; Reis et al. 2018). In this work, we found that MHB community is more affected by climate variables than ECMF MHB community (Table 1). In general, precipitation and temperature affect each ECMF MHB/MHB genus abundance in opposite ways. Within the eleven ECMF MHB genera, Cantharellus and Russula are the most affected by climatic parameters, where precipitation is clearly more important for their distribution than temperature. While Cantharellus presents a higher relative abundance in moist forests when compared with arid/semi-arid stands ( $p<0.05$, ANOVA; Supplementary Table 1), Russula distribution is negatively affected by $Q$ parameter ( $p<0.001$, ANOVA; Supplementary Table 1), differing from the few descriptions of Russula spp. intolerance to drought stress (Smith and Read, 2008). Most MHB genera are also negatively correlated with precipitation and $Q$ (Table 1). Bacillus, Rhizobium and Streptomyces are widely distributed in arid/semi-arid forests comparing with moist forest $(p<0.05$, ANOVA; Supplementary Table 1).
Semi-arid and arid cork oak stands (GR, HC-MA, HC-CT) present the highest relative abundance of total ECMF MHB genera $(92.66 \%$ and $68.59 \%$ of total identified root tips, respectively), and twofold more MHB abundance compared with moist forests (PG-ER, PG-RC; Supplementary Table 1). However, regarding specific ECMF MHB distribution among Mediterranean climates, the higher abundance of Bacillus (33-fold semi-arid vs. moist and 40-fold arid vs. moist) and Streptomyces (sixfold semi-arid vs. moist and threefold arid vs. moist) in drought-stressed forests could be related with an enhanced cork oak ectomycorrhization in such environmental conditions. However, a common behaviour for each ECMF MHB with MHB species is not described in the literature. Different Bacillus spp. were found to have opposite ecological behaviours as described by Marulanda et al. (2006, 2009). Furthermore, although Bacillus spp. were able to act as MHB in citric orchards (Freitas and Vildoso, 2004), there was not a synergistic effect with Pisolithus species for enhancing mycorrhizal colonisation in Pinus pinea host (Probanza et al. 2001). Also, Streptomyces sp. promotes mycelial growth of Amanita muscaria and Suillus bovinus, while inhibiting the Hebeloma cylindrosporum growth, due to the production of an antibiotic to which $A$. muscaria is tolerant but $H$. cylindrosporum is not (Keller et al. 2006). Therefore, while waiting for further experimental support, the hypothesis of Bacillus or Streptomyces role on cork oak ectomycorrhization in drought environments remains speculative.

The finding of new MHB partners that could promote the establishment and maintenance of mycorrhizae has been limited by the need of cultures of both ECMF and MHB for functional studies. Although recognising the limitations of this in silico analysis, the simultaneous availability of sequencing data from soil bacteria and ECM, in soil samples from different forests, is an excellent opportunity to search for putative interactions among both partners and relate them with water availability. Indeed, using the full dataset $(5,329$ bacteria vs 136 ECMF), two significant positive interactions were detected regarding two fungi and three bacteria OTUs: Cantharellus tubaeformis (ECM) vs Planctomycetes uncultured bacterium (cluster 1) and Cenococcum geophilum vs two uncultured Proteobacteria (cluster 2, Figure S1). However, we believe that their biological relevance for soil water availability is limited, at least for $C$. geophilum interaction, as $C$. geophilum is a ubiquitous ECM fungus found in all climatic regions (Reis et al 2018). The use of a more specific subdataset, in which data was curated for their ECM biological significance (19 MHB vs $52 \mathrm{ECMF} \sim \mathrm{MHB}$ ), allows a more focused analysis for their relation in different climates. With this analysis, the correlation of ECMF $\sim \mathrm{MHB}$ and MHB in cork oak stands is only significant for Lactarius and Russula genera ( $p<0.01$, ANOVA; Fig. 1). Bacillaceae and Burkholderaceae correlate directly with Russulaceae (Lactarius 


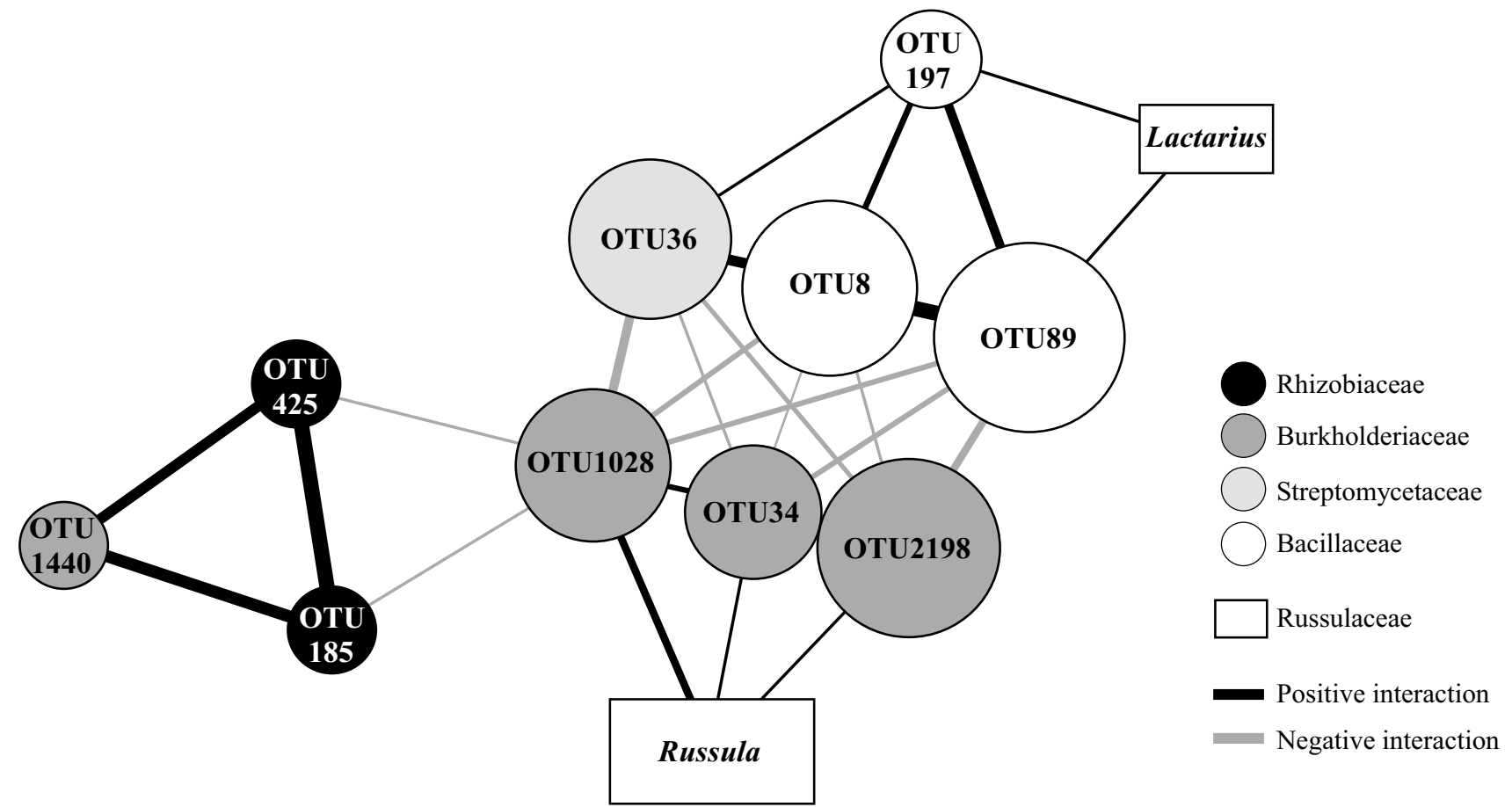

Fig. 1 Co-occurring network of positive and negative co-occurrence between MHB (circle) and ECMF MHB (square) from cork oak forests. Network calculated by Spearman's correlation analysis $(\rho>0.6)$ and significant $(p<0.01)$ correlation. Node colour is mapped to

and Russula), whereas Streptomycetaceae and Rhizobiaceae indirectly play an important role on these microbial consortia $(p<0.01$, ANOVA). Lactarius is positively influenced by the presence of two Bacillaceae OTUs, whereas Russula is positively affected by Burkholderaceae OTUs $(p<0.01$, ANOVA). Accordingly, Bacillus has been described to increase the ectomycorrhizal colonisation of Laccaria and Suillus spp., in Pseudostuga menziesii, Eucalyptus diversicolor and Pinus sylvestris (reviewed by Frey-Klett et al. 2007). In addition, an essential role of Bacillus during ectomycorrhizal colonisation (1.8- to 3.9-fold) of Eucalyptus diversicolor was described (Dunstan et al. 1998). Interestingly, we found a negative interaction of the cluster formed by Lactarius/Bacillaceae with Russula/Burkholderaceae cluster, which indicates an ecological competition between them ( $p<0.01$, ANOVA). Contrasting with this, Burkholderia has been described to increase 1.9- to 2.4-fold the ectomycorrhizal formation in the Pinus sylvestris-Lactarius rufus system (Poole et al. 2001). Regarding their specific abundance, we found that Russula and Bacillaceae are negatively influenced by precipitation and climatic $Q$ parameter ( $p<0.001$, ANOVA). The apparent independent behaviour of Burkholderaceae to climate may suggest a significant role of Russula/Burkholderaceae consortia on promoting ectomycorrhization in arid cork oak forests, which will be further enhanced by the inhibition of Lactarius/Bacillaceae phylum; the node size is mapped to the node degree. Edge colour is mapped to the type of correlation, positive (black line) and negative (grey line) and edge thickness to the value of Spearman's correlation coefficient

cluster. Indeed, although Bacillaceae abundance is enhanced in arid/semi-arid environments, Lactarius is more abundant in moist forests $(p<0.05$, ANOVA; Supplementary Table S1). Although the effect of Burkholderia on cork oak ectomycorrhization still needs experimental support, the beneficial effect of this MHB in plants under stress has been reported (Naveed et al. 2014). As far as we know, there are no studies on cork oak regarding ECMF MHB interactions, and further experimental support is needed to validate such hypothesis. Functional studies using the suggested microbial partners will definitely elucidate their role on forest sustainability, but their in vitro culture has been a strong limitation. Most of selected MHB are described as uncultivable, and most ECMF are difficult to be maintained in vitro (e.g. $C$. tubaeformis and Russula sp.). As MHB have been reported to stimulate fungal growth (Labbé et al 2014), the finding of new interaction partners could contribute for establishing strategies for stimulating ECMF fungal in vitro growth and enhance ECM establishment.

\section{Conclusions}

Cork oak forest sustainability is promoted by diverse interactions occurring between plant host, microbial community and environmental conditions. Emergent climatic changes 
are enforcing the scientific community to take a closer look on the different partners of forest ecosystems. The ability to establish ectomycorrhizae is a natural strategy for forest trees to cope with environmental variation and adaptation. In this work, the information obtained from ECMF and bacterial communities residing on cork oak forest soils was combined, and potential microbial partners of ECMFMHB were singled out. Climatic conditions directly affect these symbiotic communities. Although cork oak ECMF community has been reported to be positively affected by precipitation levels, only Cantharellus and Russula (among all ECMF MHB) are affected by precipitation. In contrast, MHB community is strongly affected by different climate variables, namely Bacillus, Rhizobium and Streptomyces. Integrating both data, negative correlations were established, and the interaction among Lactarius/Bacillaceae and Russula/Burkholderaceae singled out. We speculate that Russula/Burkholderaceae might have an important role for cork oak forest sustainability in arid environments, which will be intensified by the lower drought adaptation of competitive Lactarius/Bacillaceae. Few works have been conducted in order to better understand interactions between microbial communities within forests soils. The understanding of adaptive potential of cork oak forests, including the role played by microbial consortia for promoting their sustainability, is of utmost importance. Therefore, future research is needed in this field to help in predicting the adaptive potential and preventing drought stress consequences of forests, particularly in Mediterranean ecosystems. We hope that this work will help to create new research lines for improving forest sustainability by using ECMF and MHB.

Supplementary Information The online version contains supplementary material available at https://doi.org/10.1007/s00572-021-01027-4.

Funding This work was supported by FEDER funds through COMPETE (Programa Operacional Factores de Competitividade) and by national funds by FCT (Fundação para a Ciência e a Tecnologia) in the framework of the projects SuberControl (PTDC/ASP-SIL/28635/2017), BioISI (UIDB/04046/2020) and CIMO (UIDB/00690/2020).

\section{References}

Acácio V, Holmgren M, Moreira F, Mohren GMJ (2010) Oak persistence in Mediterranean landscapes: the combined role of management, topography, and wildfires. Ecol Society 15:40. http://www. ecologyandsociety.org/vol15/iss4/art40/

APCOR (2019) Cork sector in numbers, Associação Portuguesa de Cortiça (Portuguese Cork Association), Portugal. https://www. apcor.pt/wp-content/uploadsboletimestatisticoapcor2019.pdf

Azul AM, Sousa JP, Agerer R, Martín MP, Freitas H (2010) Land use practices and ectomycorrhizal fungal communities from oak woodlands dominated by Quercus suber L. considering drought scenarios. Mycorrhiza 20:73-88. https://doi.org/10.1007/ s00572-009-0261-2
Backer R, Rokem JS, Ilangumaran G, Lamont J, Praslickova D, Ricci E, Subramanian S, Smith DL (2018) Plant growth-promoting rhizobacteria: context, mechanisms of action, and roadmap to commercialization of biostimulants for sustainable agriculture. Front Plant Sci 9:1473. https://doi.org/10.3389/fpls.2018.01473

Bastida F, López-Mondéjar R, Baldrian P, Andrés-Abellán M, Jehmlich N, Torres IF, García C, López-Serrano FR (2019) When drought meets forest management: effects on the soil microbial community of a Holm oak forest ecosystem. Sci Total Environ 662:276-286. https://doi.org/10.1016/j.scitotenv.2019.01.233

Bonfante P, Genre A (2010) Mechanisms underlying beneficial plantfungus interactions in mycorrhizal symbiosis. Nat Commun 1:48. https://doi.org/10.1038/ncomms1046

Compant S, Clément C, Sessitsch A (2010) Plant growth-promoting bacteria in the rhizo- and endosphere of plants: their role, colonization, mechanisms involved and prospects for utilization. Soil Biol Biochem 42:669-678. https://doi.org/10.1016/j.soilbio.2009. 11.024

Dunstan WA, Malajczuk N, Dell B (1998) Effects of bacteria on mycorrhizal development and growth of container grown Eucalyptus diversicolor F. Muell. seedlings. Plant Soil 201:241-249. https:// doi.org/10.1023/A:1004329626763

Egamberdieva D, Wirth SJ, Alqarawi AA, Abd_Allah EF, Hashem A (2017) Phytohormones and beneficial microbes: essential components for plants to balance stress and fitness. Front Microbiol $8: 2104$

Felsmann K, Baudis M, Gimbel K, Kayler ZE, Ellerbrock R, Bruehlheide H, Bruckhoff J, Welk E, Puhlmann H, Weiler M et al (2015) Soil bacterial community structure responses to precipitation reduction and forest management in forest ecosystems across Germany. PLoS One 10:e0122539. https://doi.org/10.1371/journal.pone. 0122539

Forchetti G, Masciarelli O, Alemano S, Alvarez D, Abdala G (2007) Endophytic bacteria in sunflower (Helianthus annuus L.): isolation, characterization, and production of jasmonates and abscisic acid in culture medium. Appl Microbiol Biot 76:1145-1152. https://doi.org/10.1007/s00253-007-1077-7

Freitas SS, Vildoso CIA (2004) Rizobactérias e promoção do crescimento e plantas cítricas. R Bras Ci Solo 28:987-994. https://doi. org/10.1590/S0100-06832004000600007

Frey-Klett P, Garbaye J, Tarkka M (2007) The mycorrhiza helper bacteria revisited. New Phytol 176:22-36. https://doi.org/10.1111/j. 1469-8137.2007.02191.x

Ihaka R, Gentleman R (1996) R: a language for data analysis and graphics. J Comput Graphical Stat 5:299-314

Ju F, Xia Y, Guo F, Wang ZP, Zhang T (2014) Taxonomic relatedness shapes bacterial assembly in activated sludge of globally distributed wastewater treatment plants. Environ Microbiol 16:24212432. https://doi.org/10.1111/1462-2920.12355

Kataoka R, Taniguchi T, Futai K (2009) Fungal selectivity of two mycorrhiza helper bacteria on five mycorrhizal fungi associated with Pinus thunbergii. World J Microbiol Biotechnol 25:1815-1819. https://doi.org/10.1007/s11274-009-0082-7

Keller S, Schneider K, Sussmuth RD (2006) Structure elucidation of auxofuran, a metabolite involved in stimulating growth of fly agaric, produced by the mycorrhiza helper bacterium Streptomyces AcH 505. J Antibiot 59:801-803. https://doi.org/10.1038/ja.2006. 106

Kurth F, Zeitler K, Feldhahn L, Neu TR, Weber T, Krištůfek V, Wubet T, Herrmann S, Buscot F, Tarkka MT (2013) Detection and quantification of a mycorrhization helper bacterium and a mycorrhizal fungus in plant-soil microcosms at different levels of complexity. BMC Microbiol 13:205. https://doi.org/10.1186/ 1471-2180-13-205

Labbé JL, Weston DJ, Dunkirk N, Pelletier DA, Tuskan GA (2014) Newly identified helper bacteria stimulate ectomycorrhizal 
formation in Populus. Front Plant Sci 5:579. https://doi.org/10. 3389/fpls.2014.00579

López-Mondéjar R, Voríšková J, Vetrovský T, Baldrian P (2015) The bacterial community inhabiting temperate deciduous forests is vertically stratified and undergoes seasonal dynamics. Soil Biol Biochem 87:43-50. https://doi.org/10.1016/j.soilbio.2015.04.008

Maghnia F, Abbas Y, Mahé F, Prin Y, Ghachtouli N, Duponnois R, Sanguin H (2019) The rhizosphere microbiome: a key component of sustainable cork oak forests in trouble. For Ecol Manag 434:29-39. https://doi.org/10.1016/j.foreco.2018.12.002

Malek Ž, Verburg PH (2018) Adaptation of land management in the Mediterranean under scenarios of irrigation water use and availability. Mitig Adapt Strateg Glob Change 23:821-837. https://doi. org/10.1007/s11027-017-9761-0

Marulanda A, Barea JM, Azcon R (2006) An indigenous droughttolerant strain of Glomus intraradices associated with a native bacterium improves water transport and root development in Retama sphaerocarpa. Microb Ecol 52:670-678. https://doi.org/ 10.1007/s00248-006-9078-0

Marulanda A, Barea JM, Azcon R (2009) Stimulation of plant growth and drought tolerance by native microorganisms (AM fungi and bacteria) from dry environments: mechanisms related to bacterial effectiveness. J Plant Growth Regul 28:115-124. https://doi.org/ 10.1007/s00344-009-9079-6

Naveed M, Mitter B, Reichenauer T, Wieczorek K, Sessitsch A (2014) Increased drought stress resilience of maize through endophytic colonization by Burkholderia phytofirmans PsJN and Enterobacter sp. FD17. Environ Exp Bot 97:30-39. https://doi.org/10. 1016/j.envexpbot.2013.09.014

Pausas JG, Millán MM (2019) Greening and browning in a climate change hotspot: the Mediterranean basin. Bioscience 69:143-151. https://doi.org/10.1093/biosci/biy157

Pii Y, Mimmo T, Tomasi N, Terzano R, Cesco S, Crecchio C (2015) Microbial interactions in the rhizosphere: beneficial influences of plant growth-promoting rhizobacteria on nutrient acquisition process. A review Biol Fertil Soils 51:403-415. https://doi.org/ 10.1007/s00374-015-0996-1

Poole EJ, Bending GD, Whipps JM, Read DJ (2001) Bacteria associated with Pinus sylvestris-Lactarius rufus ectomycorrhizas and their effects on mycorrhiza formation in vitro. New Phytol 151:743-751. https://doi.org/10.1046/j.0028-646x.2001.00219.x
Probanza A, Mateos JL, Garcia JAL, Ramos B, Felipe MR, Mafiero FJG (2001) Effects of Inoculation with PGPR Bacillus and Pisolithus tinctorius on Pinus pinea L. growth, bacterial rhizosphere colonization, and mycorrhizal infection. Microbial Ecol 41:140148. https://doi.org/10.1007/s002480000081

Reis F, Tavares RM, Baptista P, Lino-Neto T (2017) Mycorrhization of Fagaceae forests within Mediterranean ecosystems. Mycorrhiza Function, Diversity, State of the Art, 4th edn. Springer, Berlin. https://doi.org/10.1007/978-3-319-53064-2_6

Reis F, Valdiviesso T, Varela C, Tavares RM, Baptista P, Lino-Neto $\mathrm{T}$ (2018) Ectomycorrhizal fungal diversity and community structure associated with cork oak in different landscapes. Mycorrhiza 28:357-368. https://doi.org/10.1007/s00572-018-0832-1

Reis F, Soares-Castro P, Costa D, Tavares RM, Baptista P, Santos PM, Lino-Neto T (2019) Climatic impacts on the bacterial community profiles of cork oak soils. Appl Soil Ecol 143:89-97. https://doi. org/10.1016/j.apsoil.2019.05.031

Rigamonte TA, Pylro VS, Duarte GF (2010) The role of mycorrhization helper bacteria in established and action of the ectomycorrhizae. Braz J Microbiol 41:832-840. https://doi.org/10.1590/S151783822010000400002

Shannon P, Markiel A, Ozier O, Baliga NS, Wang JT, Ramage D, Amin N, Schwikowski B, Ideker T (2003) Cytoscape: a software environment for integrated models of biomolecular interaction networks. Genome Res 13:2498-2504. https://doi.org/10.1101/ gr.1239303

Smith S, Read D (2008) Mycorrhizal symbiosis, 3rd edn. Academic, New York and Harcourt Brace

Tate EL, Gustard A (2000) Drought definition: a hydrological perspective. Drought and Drought Mitigation in Europe. Springer, Netherlands, pp 23-48

Ząbkiewicz A, Myga-Nowak M, Bandurska K, Paczyńska J, Szybecka A, Krupa P (2014) The application of PCR reaction for identification of MHB bacteria species Arch Environ Prot 40. https://doi. org/10.2478/aep-2014-0020

Publisher's Note Springer Nature remains neutral with regard to jurisdictional claims in published maps and institutional affiliations. 